\title{
Study of the Thermal, Rheological, Morphological and Mechanical Properties of Biocomposites Based on Rod-Of Typha/HDPE Made up of Typha Stem and HDPE
}

\author{
Babacar Niang1*, El Hadj Babacar Ly¹, Abdou Karim Diallo', Nicola Schiavone ${ }^{2,3}$, \\ Haroutioun Askanian'2,3, Vincent Verney ${ }^{2,3}$, Ansou Malang Badji1, Mahmoud Kalid Diakite1, \\ Diéne Ndiaye ${ }^{1}$
}

\author{
${ }^{1}$ Section Physique Appliquée, Unité de Formation et de Recherche de Sciences Appliquées et de Technologies, Université Gaston \\ Berger, Saint Louis, Sénégal \\ ${ }^{2}$ Institut de Chimie de Clermont-Ferrand, Université Blaise Pascal, Clermont-Ferrand, France \\ ${ }^{3}$ CNRS, UMR 6296, ICCF, Université Blaise Pascal, Aubière, France \\ Email: ^babsenergy10@gmail.com
}

How to cite this paper: Niang, B., Ly, E.H.B., Diallo, A.K., Schiavone, N., Askanian, H., Verney, V., Badji, A.M., Diakite, M.K. and Ndiaye, D. (2018) Study of the Thermal, Rheological, Morphological and Mechanical Properties of Biocomposites Based on Rod-Of Typha/HDPE Made up of Typha Stem and HDPE. Advances in Materials Physics and Chemistry, 8, 340-357. https://doi.org/10.4236/ampc.2018.89023

Received: July 24, 2018

Accepted: September 11, 2018

Published: September 14, 2018

Copyright $\odot 2018$ by authors and Scientific Research Publishing Inc. This work is licensed under the Creative Commons Attribution International License (CC BY 4.0).

http://creativecommons.org/licenses/by/4.0/

\begin{abstract}
The thermal, rheological and morphological properties of composite biomaterials made with mixture of high density polyethylene and typha rod powder (RD) were evaluated. The dynamic mechanical behavior of the samples was studied with $25 \%$, 35\% and $45 \%$ typha stem powder concentrations. The viscoelastic properties are mainly related to the nature of the polymer and the typha stem powder. Storage $\left(G^{\prime}\right)$ and loss $\left(G^{\prime \prime}\right)$ moduli increased significantly, depending on the amount of powder in the molten mixture. After a viscosity increase was noticed in low frequency, it decreased in high frequencies, which demonstrates the pseudo-plasticity effect. Morphological and thermal characterization results have shown the dispersion state of the powder and its ability to modify the kinetics crystallization of biocomposites.
\end{abstract}

\section{Keywords}

Biocomposite, Thermal, Rheological, Morphological, Mechanical Properties

\section{Introduction}

The development of polymeric biocomposites made up of natural fibers or wood particles as reinforcing components is attracting more and more attention from the industrial world because synthetic fibers are expensive, non-biodegradable 
and their production consumes energy, with a negative impact on the environment [1]. The use of wood fibers and wood flour as a reinforcing agent for composite polymers has increased dramatically compared to the traditional synthetic fibers due to their advantages in terms of quality and production cost. Natural wood particles (fibers or granules) have been involved in the development of innovative, lightweight, solid materials and can be used in the engineering field. In addition, they are renewable, recyclable, biodegradable and very eco-friendly.

On the other hand, wood flour plays a major role in improving the elasticity modulus and the flexural strength of the composite [2]. However, the mechanical performance of WPC differs from kind of wood. For example, even though the flexural strengths of WPC and wood are close, the elastic properties of wood are higher. This statement is based on data comparison and experimental results [3].

Fiber content is an influential factor in the properties of WPC. Gisele et al. [4] studied the effect of wood content on the thermal behavior and molecular dynamics of composites made up of PVC and wood. They found that progressive addition of wood flour resulted in a small but gradual improvement in the decomposition temperature composites-while the glass transition temperature remained virtually unchanged-and a gradual decrease in relaxation time values $\left(\mathrm{T}_{1}\right)$. $\mathrm{H}$ values have been observed with an increase in wood content, which indicates that composites have become less rigid.

Four formulations were made by Nourbakhsh and Ashori with 10\%, 20\%, $30 \%$ and $40 \%$ fiber mass concentrations (in terms of weight) to study the mechanical properties of poplar/PP composites. They observed that composites with $30 \%$ and $40 \%$ fibers allowed ideal reinforcement at $190^{\circ} \mathrm{C}$ to increase the tensile and flexural strength of the PP, and the modulus increased and the elongation and impact properties decreased as the fiber content increased. Other authors stated that there is an increase in torque and viscosity as wood fiber content increases at steady state.

A range of natural materials have been used for the manufacture of wood-polymer composites. Among those materials, wood fibers were found very interesting in the areas of basic research and applications due to their ease of handling and high availability [5] [6]. Many factors such as particle distribution, shape and size, chemical surface nature and impurity content have very large influence on the quality of the wood fiber. Among these factors, fiber size is the most determinant on the mechanical behavior of a composite made up of wood and polymer. However, the experimental results regarding fiber size role in mechanical behavior are contradictory. The experiments conducted by Maiti and Singh [7] on different wood particle sizes without coupling agent showed that despite poor adhesion between fiber content and the plastic, the sample produced by extrusion had an increasing elasticity modulus with a decreasing particle size. In contrast, Chen et al. [8] studied the influence of wood particle size 
on wood/HDPE composites and found that composites made up of larger wood particles had greater strength. Furthermore, the addition of wood content to the thermoplastic polymer is combined with a considerable increase in viscosity in the molten state [9] [10].

Despite the rapid growth in the use of wood-plastic composite (WPC) in automotive and other industries [11] [12], there is limited information published in the field of WPC rheology in West Africa. In fact, people use a large number of plastic bags; the residues of these bags released in the nature constitute a serious pollution issue for both consumers and environmentalists. Rheology could allow the biocomposite development with a good interpretation of the interaction between the wood and the polymer matrix.

The mechanical and thermal properties and the dynamic behavior of the modified PP/WF composite were studied by Hristov and Vasileva [13]. Other authors studied the viscoelastic behavior; surface tearing and wall slip phenomena of high density polyethylene (HDPE)/WF composites [14] [15]. The rheological behavior of the HDPE/WF composite under steady shear and extension flux has been studied by Li and Wolcott [16]. They found that the extension viscosity is not significantly affected by the wood content. They also analyzed the composite slide and reported that the rate of this phenomenon is influenced by the wood content [17]. In another study, these authors examined wood content, particles size and maleated polyethylene effects on the rheological properties of the maple/HDPE composite [18]. The elastic component is given by the dynamic storage modulus, which indicates the inherent stiffness of the material while the mechanical damping or the internal friction $(\tan \partial)$ indicates the amount of energy dissipated in the form of heat during the deformation [19].

Our study focuses on the use of Typha australis fibers for the manufacture of composite material. Typha australis is an aquatic plant found on wetlands and it belongs to the Typhaceae family. This plant, which can be $3 \mathrm{~m}$ high [20], is particularly widespread on the Senegal River Valley. Typha australis is now considered a pest. Indeed, its proliferation on the Senegal River Valley affects the valley's ecosystem and reduces the socio-economic activities of local communities. Typha plants are widely used in wetland construction for ecological restoration [21] and wastewater treatment [22] [23]. In addition, Typha is also the raw material for heat preservation [24], weaving and paper [25] because of the length of its fiber, the plant's toughness, and its heat preservation performance.

The final objective of this study is to evaluate the rheological, thermal, mechanical, and morphological properties of original biocomposites made up of typha stem and high-density polyethylene.

\section{Experimentation}

High density polyethylene (HDPE) has been used in the engineering field because of its good physical and mechanical properties.

It is one of the most versatile commercial polymers with its semi-crystalline 
nature allowing treatment over a wide temperature range. The crystalline phase of the polymer provides resistance, while the amorphous phase provides flexibility [26]. HDPE is the most widely used polymer matrix for WPCs because of its relatively low processing temperature and property of being easily processable [27]. HDPE was supplied in the form of granules by Nova Chemicals. Its melt index was $7.0 \mathrm{~g} / 10 \mathrm{~min}$ at $190^{\circ} \mathrm{C}$ and the density at room temperature was $0.962 \mathrm{~g} / \mathrm{cm}^{3}$. Thus, prior to any mixing operation, the wood powder was oven dried at $105^{\circ} \mathrm{C}$ for 24 hours to remove moisture less than $1 \%$.

No further processing took place on the polymer before use. The composite materials were obtained by mixing in a $7 \mathrm{~cm}^{3}$ co-rotating twin screw microcompounder minilab mixer. For the extraction of harmful gases, the hood was open. In a first step, the polymer is introduced for $5 \mathrm{~min}$ at $180^{\circ} \mathrm{C}$ and the speed of the screw is set at $100 \mathrm{rpm}$. In a second step, typha stem powder is introduced. The system is mixed for $10 \mathrm{~min}$ at $180^{\circ} \mathrm{C}$ at $100 \mathrm{rpm}$ (Figure 1). After this phase each sample is sandwiched for $1 \mathrm{~min}$ between two Teflon sheets and pressed at $180^{\circ} \mathrm{C}$ under a pressure of 200 bars to obtain films ranging from 100 to 200 microns thick for spectroscopic analysis, or of a few millimeters thickness for the study of different macroscopic properties. With the polymer matrix (HDPE), four formulations were produced with different typha stem powder contents at the Clermont-Ferrand Institute of Chemistry (ICCF) laboratory in France (Table 1). The temperature profile in the machine was kept below $180^{\circ} \mathrm{C}$ to minimize thermal degradation of the powder.

\section{Composition}

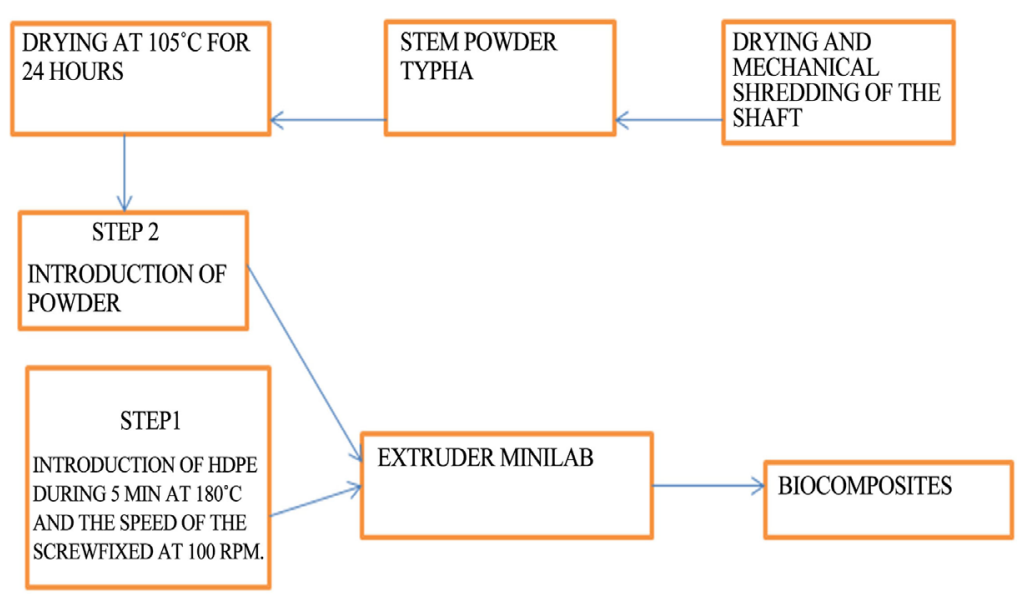

Figure 1. Schematic diagram of the composites biomaterials.

Table 1. The percentage samples of wood and polymer.

\begin{tabular}{lcc}
\hline RDHDPEC0 & 100 & 0 \\
\hline RDHDPEC1 & 75 & 25 \\
RDHDPEC2 & 65 & 35 \\
RDHDPEC3 & 55 & 45
\end{tabular}




\section{Characterization}

\subsection{Characterization of the Thermal Stability of the Composite}

\subsubsection{Thermogravimetric Analysis (TGA)}

Thermogravimetry is a technique that measures the mass variation of a sample, when it is subjected to temperature programming in a controlled atmosphere. This variation can be a loss of mass (vapor emission) or a mass gain (gas fixation, oxidation, etc.). The sample is weighed and the baseline established, then the sample is subjected to temperature rise. At different temperatures, chemical reactions can release gaseous species, or form oxides causing a mass variation of the sample. This mass change is recorded, according to the temperature. A large number of transitions (melting, crystallization, glass transition...) do not imply a mass variation. These transitions, which are not detected by thermogravimetric analysis, can be differential thermal and enthalpic analyses. Submitted to these high temperatures, wood and synthetic polymers are susceptible to have their mechanical properties deteriorated. It is necessary to optimize the temperature during the implementation of the WPC. This method of analysis is often used to determine the characteristics of materials such as oxidation kinetics, absorption, hydration, etc. [28]. For our tests, we used a Mettler Toledo thermogravimetric analyzer to measure the mass variations of the samples. Heating was carried out at temperatures ranging from $30^{\circ} \mathrm{C}$ and $600^{\circ} \mathrm{C}$, setting during the analysis a thermal rate of $10^{\circ} \mathrm{C} / \mathrm{min}$. Nitrogen is used as carrier gas. This analysis makes it possible to know the thermal decomposition temperature of a polymer. The loss of mass is recorded according to a temperature programmed with a given gradient.

\subsubsection{Differential Scanning Calorimetry Analysis}

Differential scanning calorimetry was used to analyze the thermal properties of composites. Samples with different wood particle concentrations were subjected to a temperature scanning ranging from $25^{\circ} \mathrm{C}$ to $210^{\circ} \mathrm{C}$, at a heating rate of $10^{\circ} \mathrm{C} /$ min under a harmful inert gas (nitrogen). We performed two cycles (heating-cooling) under controlled atmosphere during the temperature programming. The fitness effects (processing) and the residual stresses in materials of thermal origin were eliminated during the first cycle. Then, the second cycle made it possible to measure the melting temperature $\mathrm{Tm}$, the melting enthalpy $\Delta \mathrm{H}_{\mathrm{f}}$, the crystallinity degree of semi-crystalline polymers and the heat capacity variation $\mathrm{C}_{\mathrm{p}}$ of the biocomposites.

\subsection{Rheological Characterization}

The rheological characterization of the composites functions was carried out using dynamic low amplitude oscillatory shear tests. This method makes it possible to measure the dynamic properties of composites such as dynamic moduli $\mathrm{G}^{\prime}$, $\mathrm{G}^{\prime \prime}$, and the loss, complex and storage viscosity respectively $\eta^{\prime}, \eta^{\prime \prime}$, and $\eta^{*}$. The dynamic elastic moduli $\mathrm{G}^{\prime}$ and $\eta^{\prime \prime}$, help measure the elastic energy stored in the 
deformed material. This energy is reversible; it helps the material partially recover its shape before the deformation. While the dynamic moduli G" and $\eta^{\prime}$ represent the dynamic loss modulus, they correspond to the amount of energy dissipated by the materials due to the interaction between the molecular chains of the polymers in shear. The variation of these moduli, according to the frequency and at a temperature equal to $180^{\circ} \mathrm{C}$ for biocomposites with different wood contents, is studied.

\subsection{Morphological Characterization}

The state of dispersion of the wood inside the polymeric matrix was analyzed using optical microscopy on $100-200 \mathrm{~mm}$ thick samples. The fractured samples were coated with a thin gold layer to avoid electrostatic charging during examination. SEM was used to obtain microphotographs of the fracture surfaces of the wood composites. These fractures have been performed in liquid nitrogen to avoid any deformation. SEM has been performed using a Fei Quanta 400 microscope working at $20 \mathrm{kV}$ [29].

\section{Results and Discussions}

\subsection{Thermal Stability of the Composite}

With a Mettler Toledo thermogravimetric analyzer, we obtain measures the mass variations of the samples (Figure 2: Heating ranging from $30^{\circ} \mathrm{C}$ to $600^{\circ} \mathrm{C}$ for biocomposites, a thermal rate of $10^{\circ} \mathrm{C} / \mathrm{min}$ being set during the analysis). $\mathrm{Ni}$ trogen is used as carrier gas. Through this analysis, it is possible to know the thermal decomposition temperature of a polymer.

The thermal degradation of composites made up of wood fiber and pure HDPE in regard to the temperature is illustrated in Figure 2(a). From the thermogravimetric curves, we notice in the first place a loss of mass for the different samples containing wood, which corresponds to the loss of water. By $225^{\circ} \mathrm{C}$, starts a mass variation with a change in the shape of the curve. It corresponds to the degradation start temperature of wood. The curve of the first derivative is associated with the TGA curve.

The pure HDPE shows negligible loss of mass at temperatures below $370^{\circ} \mathrm{C}$. The significant decrease in mass loss starts from the temperature above $410^{\circ} \mathrm{C}$. The TGA of typha stem fiber shows a two-step degradation process with an initial transition of about $100^{\circ} \mathrm{C}$ due to moisture evaporation.

It is known that cellulose in wood contains many strongly hydroxyl groups. The initial degradation temperature $\left(\mathrm{T}_{\mathrm{d}}\right)$ of typha plating was $240^{\circ} \mathrm{C}$, and the maximum decomposition temperature was $381^{\circ} \mathrm{C}$. Cellulosic substances normally have three degradation stages. The depolymerization of hemicelluloses is between $150^{\circ} \mathrm{C}$ and $350^{\circ} \mathrm{C}$, the random cleavage of the glycosidic bonds of cellulose occurs between $280^{\circ} \mathrm{C}$ and $350^{\circ} \mathrm{C}$, and the degradation of lignin occurs between $250^{\circ} \mathrm{C}$ and $500^{\circ} \mathrm{C}$ [30] [31].

In contrast, in other samples (Figure 2(a) and Figure 2(b)), depending on the 
reinforcement rate inserted in the polymer matrix in both cases, a decrease in weight loss around $100^{\circ} \mathrm{C}$ due to the elimination of the moisture was observed. Because of the high flammability of cellulose, the addition of wood makes the composite less thermally stable [32]. The TGA measurements indicate that, when the polymer is heated, its thermal stability is generally evaluated from the loss of mass and its molecular weight decreases sharply due to the degradation of the molecular chains [33].

The degradation mechanism of wood/HDPE composites has not been sufficiently understood. However, the possible reasons for the increase in the thermal stability of these mixtures can be explained by the fact that the crystals in the amorphous phase of the polymer are initially protected by the surrounding polymer chains. Similarly, in the case of pure HDPE, the degradation began at around $450^{\circ} \mathrm{C}$ and the maximum decomposition rate appeared at $495^{\circ} \mathrm{C}$. The degradation temperature range (about $450^{\circ} \mathrm{C}$ ) of this polymer is displaced at lower temperatures.

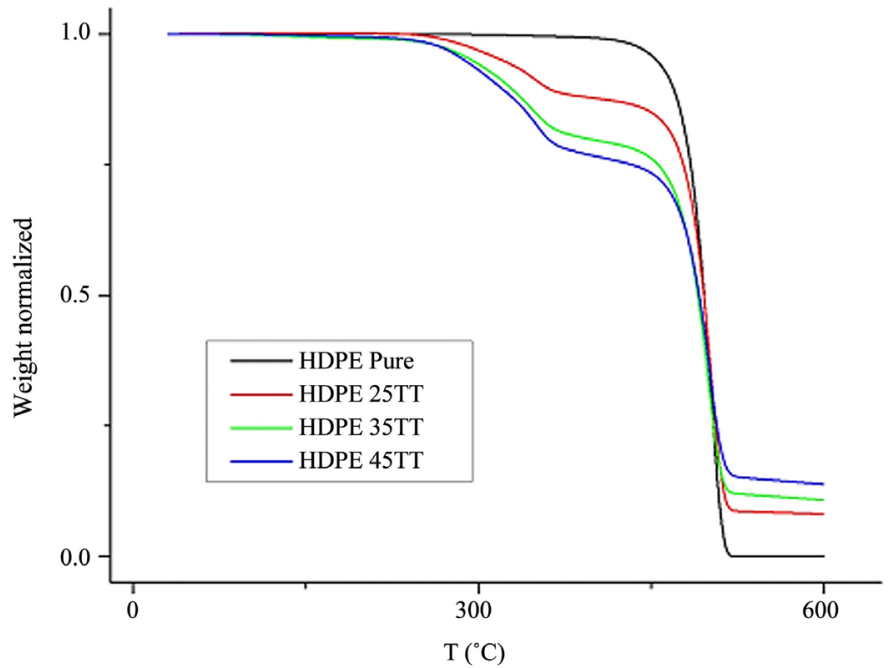

(a)

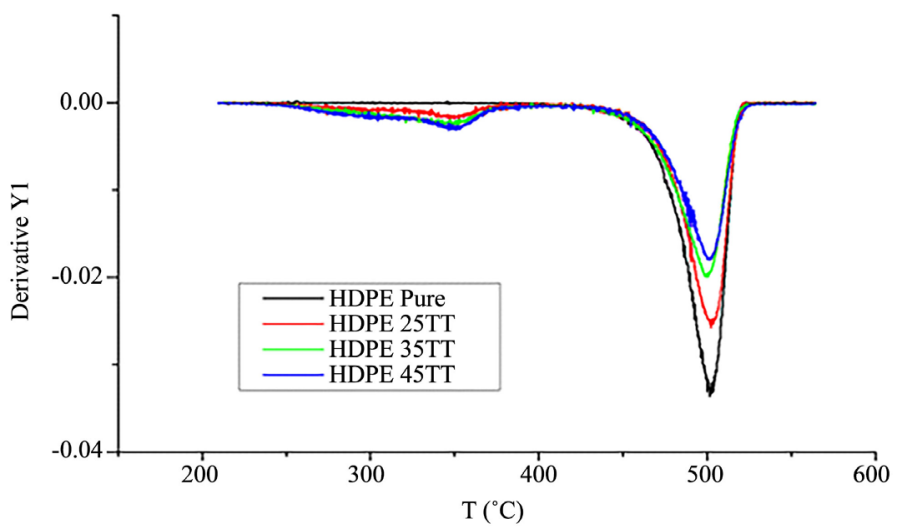

(b)

Figure 2. (a) TGA thermograms of pure HDPE and its composites; (b) DTG curves of decomposition of pure HDPE and its composites. 
Figure 2(a) shows the TGA curves of the pure polymer matrix and its composites.

The evolution of the mass is generally represented in relative values (in \%) with respect to the initial mass of the sample. The derivative of the TGA curve thus obtained, the DTG curve, is often represented, according to the time or temperature for better clarity. It shows the speed of the evolution of the mass in $(\%) / \min$ or in $(\%) /{ }^{\circ} \mathrm{C}$.

In DTG Figure 2(b), the thermal degradation has two levels.

The temperature ranges of the first stages show dehydration up to $320^{\circ} \mathrm{C}$ approximately, a separation of the moisture and the combined water of the wood. The temperature at the beginning of the dehydration is taken as a measure of the thermal stability of the WPC.

These results are confirmed by those in the literature [34] [35] [36]. Therefore, it would be necessary to adjust the temperatures to around $200^{\circ} \mathrm{C}$ to prevent their degradation during manufacturing processes (extrusion). Mass loss according to time or temperature is an irreversible process due to thermal degradation. It can be concluded that the cellulose components and hemicellulose of wood are the main contributors to the decomposition between $250^{\circ} \mathrm{C}$ and $370^{\circ} \mathrm{C}$, while lignin is mainly responsible for the carbonization of wood at a temperature above $400^{\circ} \mathrm{C}$.

The loss of mass during its first stages are of $8 \%, 11 \%$ and $16.7 \%$ respectively for composites made up at $25 \%, 35 \%$ and $45 \%$ of typha powder. The remaining polymers decompose during the second stages. The sample loses a total of $92 \%$ of its mass up to $600^{\circ} \mathrm{C}$. From the curve of this example, a thermal effect start temperature of $210^{\circ} \mathrm{C}$ can be observed. The mass loss information obtained by thermogravimetric analysis does not specify the types of decomposition products. This is only possible if the TGA device is coupled with a suitable interface. For example, equipment for gas analysis provided with an infrared spectrometer and gas-filled cells or a mass spectrometer.

\subsection{Differential Scanning Calorimetry}

The DSC measurements were conducted on the various typha stem composite samples. The parameters resulting from these measurements are the melting temperature $\left(\mathrm{T}_{\mathrm{m}}\right)$, the crystallization temperature $\left(\mathrm{T}_{\mathrm{c}}\right)$, the crystallization enthalpy $\left(\Delta \mathrm{H}_{\mathrm{c}}\right)$, the melting enthalpy $\left(\Delta \mathrm{H}_{\mathrm{m}}\right)$, and the crystallinity percentage $(\%)$. The figure shows thermograms of composite samples containing different powder percentages. The results of these physical parameters quoted below were summarized in the following table.

Figure 3 shows the DSC thermograms of the cooling curves (Figure 3(a)) and the melting curves (Figure $3(\mathrm{~b})$ ) of HDPE and its composites.

Like the thermograms in the figures, the thermograms of all the samples show endothermic peaks between $133^{\circ} \mathrm{C}$ and $135^{\circ} \mathrm{C}$ during heating and exothermic peaks between $118^{\circ} \mathrm{C}$ and $120^{\circ} \mathrm{C}$ during cooling. 


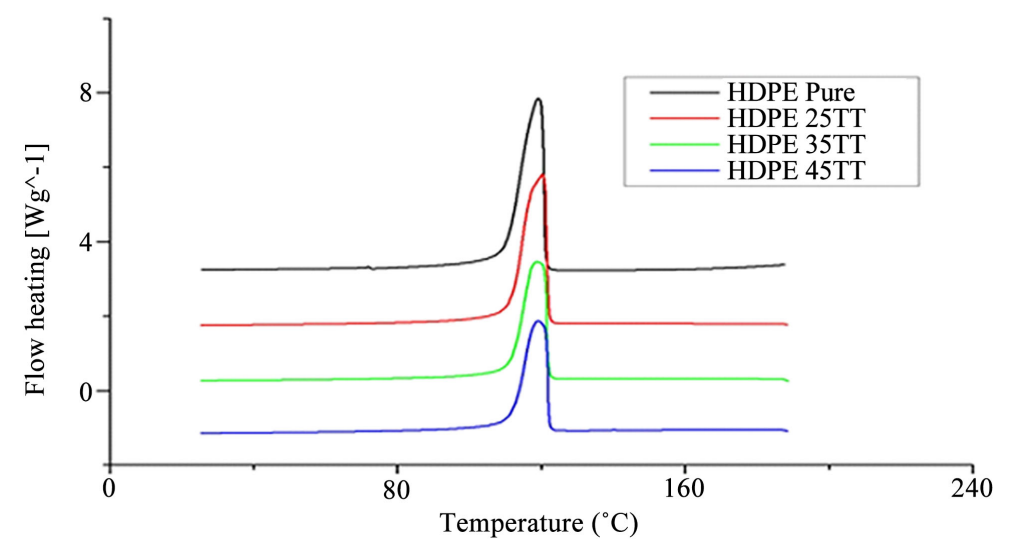

(a)

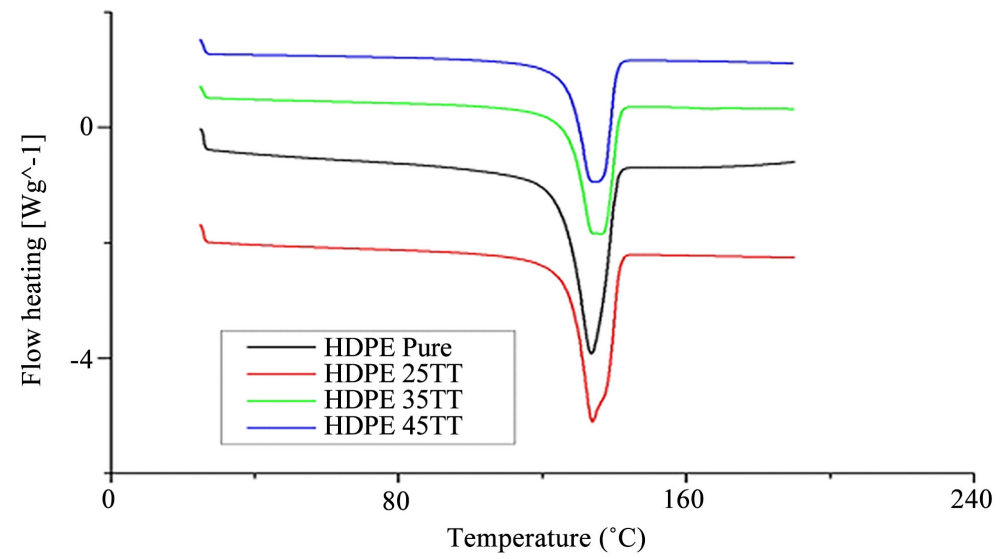

(b)

Figure 3. (a) DSC cooling thermograms of neat HDPE and its composites containing different rates of typha rod, cooling; (b) DSC fusion thermograms neat HDPE and its composites containing different rates of typha rod, melting.

We notice that the addition of wood increases the melting temperature. Indeed, we notice an increase of the melting temperature with the wood percentage (Table 2).

This can be explained by the fact that the polymer needs heat to melt, but powder is not a good thermal conductor. Typha stem particles intercalated in the polymer matrix act as insulators and slow down the heat circulation process by conduction [14]. An increase in the degree of crystallinity is observed by adding the typha stem powder. The increase in the crystallinity level may be due to changes in the molecular weight that occurs during the degradation of the polymer, resulting in the breaking of chains and probably a secondary crystallization. In the composite, the increase in crystallinity is due to a decrease in molecular weight [19].

\subsection{Rheological Behavior}

The rheological properties of all the samples in the molten state were determined by mechanical dynamic measurements. The conservation modulus G', the loss 
modulus $G^{\prime \prime}$ and the dynamic viscosity $\eta^{*}$ were measured according to the frequencies scanned between 0.1 to $100 \mathrm{rad} / \mathrm{s}$.

Figure 4 and Figure 5 show the variation of the dynamic moduli (G') and $\left(G^{\prime \prime}\right)$ and the viscosity according to the frequency with different percentages of typha.

Table 2. Thermal properties of pure HDPE and its composites.

\begin{tabular}{cccccc}
\hline Sample & $\Delta \mathrm{H}_{\mathrm{f}}\left(\mathrm{J} \cdot \mathrm{g}^{-1}\right)$ & $\Delta \mathrm{H}_{\mathrm{C}}\left(\mathrm{J} \cdot \mathrm{g}^{-1}\right)$ & $\mathrm{T}_{\mathrm{f}}\left({ }^{\circ} \mathrm{C}\right)$ & $\mathrm{T}_{\mathrm{c}}\left({ }^{\circ} \mathrm{C}\right)$ & $\mathrm{X}_{\mathrm{c}}(\%)$ \\
\hline HDPE PUR & 179.15 & 181.74 & 133.69 & 119.27 & 61.1 \\
HDPE 25 & 156.73 & 163.94 & 133 & 120.45 & 71.3 \\
HDPE 35 & 119.67 & 128 & 136.53 & 118.98 & 62.8 \\
HDPE 45 & 107.07 & 119.75 & 135.73 & 119.18 & 66.5 \\
\hline
\end{tabular}

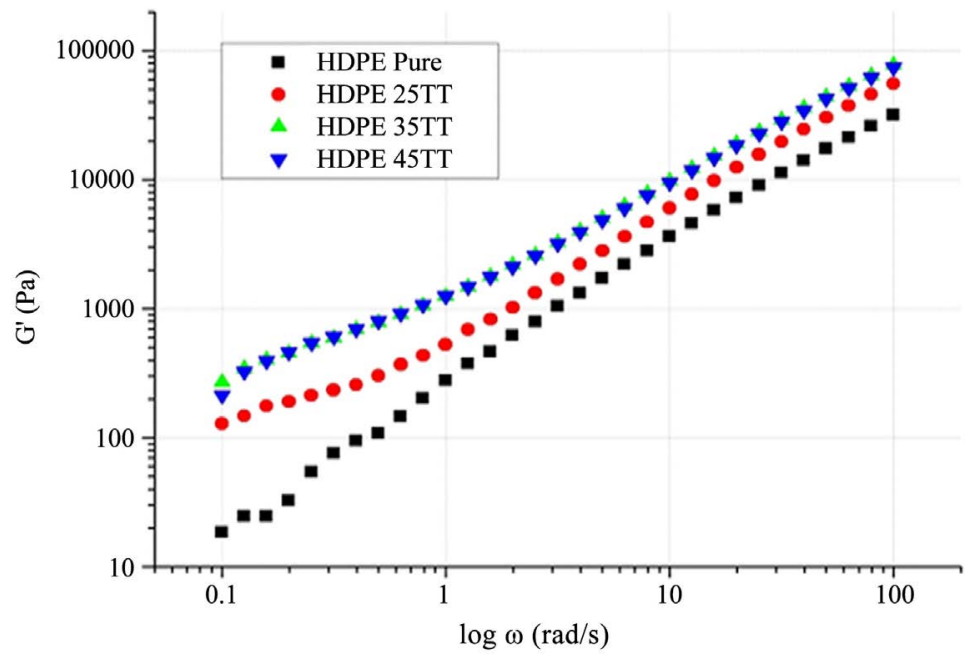

Figure 4. The variation of the dynamic moduli $\left(\mathrm{G}^{\prime}\right)$ and $\left(\mathrm{G}^{\prime \prime}\right)$ according to the frequency with different percentages of typha stem.

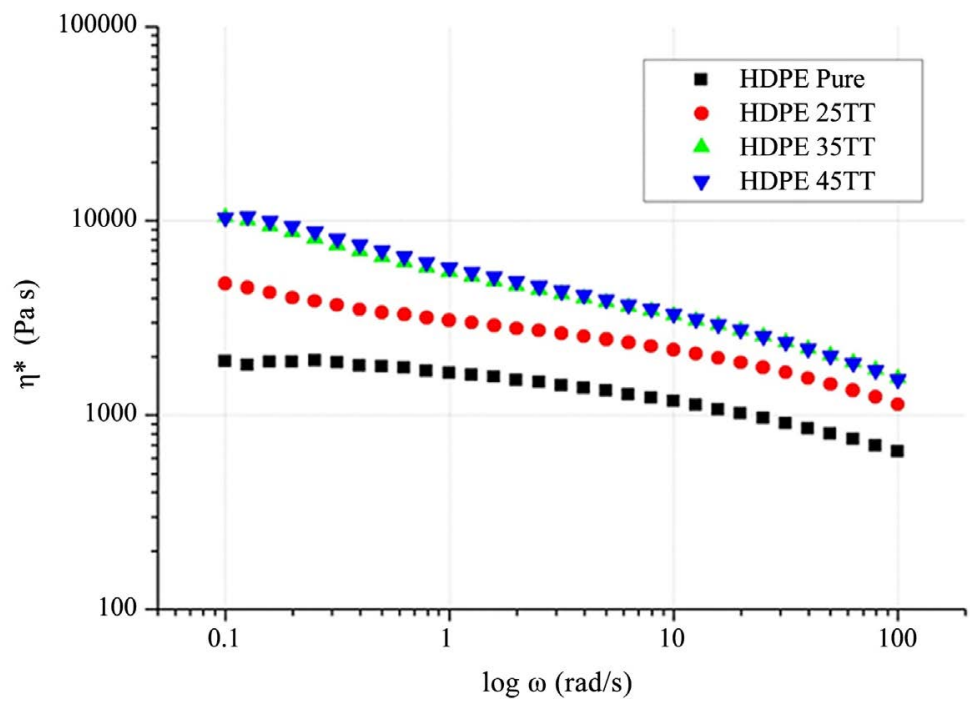

(a) 


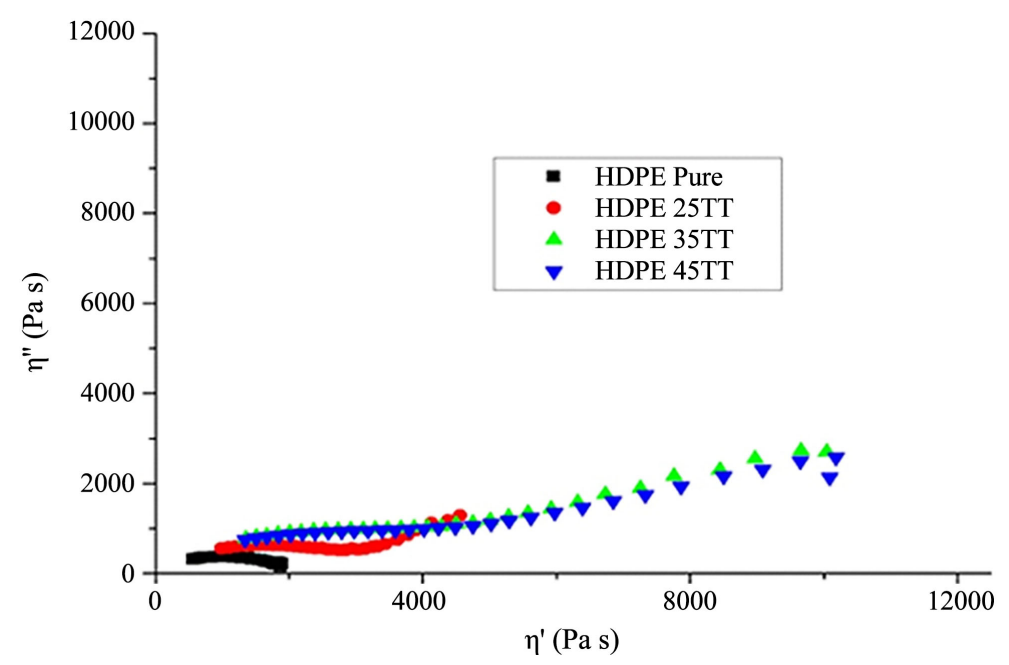

(b)

Figure 5. (a) Frequency variations of the complex viscosity of pure HDPE and its composites at $\mathrm{T}=180^{\circ} \mathrm{C}$; (b) Complex plane diagrams for the WPC (upper right curve for neat $\mathrm{HDPE}$ ) at $\mathrm{T}=180^{\circ} \mathrm{C}$.

The dynamic storage $\left(G^{\prime}\right)$ and loss $\left(G^{\prime \prime}\right)$ moduli tend to increase with the typha stem powder content (Figure 4). This can be translated by a more elastic behavior for high contents. Quite obviously, the complex viscosity of pure polymer gradually increases with the increase of powder content from $25 \%$ to $45 \%$ (Figure 5). Indeed, in filled systems, wood particles disturb the flow of the pure polymer and hinder the mobility of chain segments in the direction of flow, its particles are often in the form of aggregates.

This can also be explained by an inhomogeneous dispersion and by the alignment of the cellulosic phase in the composites. These observations are confirmed by those provided in literature [31] [37]. In addition, G' and G" moduli tend to have the same values beyond $35 \%$. Shear thinning behavior of the molten mass was observed, the viscosity of the composites is strongly influenced by the shear rate. The composites showed substantially the same viscosity above $35 \%$. This phenomenon is probably due to the alignment of the fibers at high shear rates, which reduces the collisions between particles [38]. Indeed, the fluidity of the mixture is increased by an increase in the oscillation frequency, which decreases the complex viscosity. This reduction in viscosity shows the pseudo-plastic nature of materials in the molten state.

In the low frequency domain, the viscosity increases dramatically as the fiber content in the composite material increases. The addition of fillers has an influence on the rigidity, the density and the viscoelastic behavior of a polymer [37] [38] [39]. The highest value of complex viscosity was observed with the composite containing $45 \%$ of typha stem masses. In addition, the presence of agglomerates (due to high content) caused flow resistance and an increase in the viscosity of the composites. This behavior can be explained by a higher interaction rate between the polymer matrix and the content, which forces the mixture to have 
greater shear stress and longer relaxation times for the composites to flow [40]. The rheological properties of high density polyethylene exhibit the same shear thinning behavior.

The elasticity moduli demonstrate an improvement in the dynamic behavior of composites.

\subsection{Scanning Electron Microscopy}

The microstructure of the wood/HDPE composite shown in the figure is observed (after extrusion) using a scanning electron microscope. It is well known that the properties of wood/polymer composites strongly depend on the dispersion of the wood and the polymer matrix.

Visual observation reveals fairly smooth surface in composites (HDPE/Typha stem) probably due to a medium inter-facial adhesion. The wood particles are detected as white dots in Figures 6(a)-(c).

When we compare Figure 6(b) and Figure 6(c), we notice that the dispersion is better in Figure 6(b), where there is less wood. These two results show that the dispersion decreases with a high content rate. For blends containing HDPE/RD (Figure 6(a)), we can see that the composite phase appears to be more uniform than the figures (Figure 6(b) and Figure 6(c)). The results suggest a smoother surface, which would promote interfacial adhesion between the two elements. From the images in Figure 6, the observations in Figure 6(a) are contrasted with the surface texturing of the samples from Figure 6(b) and Figure $6(\mathrm{c})$.

The SEM micrographs presented (Figure 6(b) and Figure 6(c)) showed that the wood particles are more superficial on the surface of the samples.

When the wood content increased up to $45 \%$, the particles were not uniformly distributed in the HDPE matrix. The matrix did not sufficiently encapsulate the solid microparticles and microfibrils of wood. However, large aggregates were found and the aggregated size increased significantly in these surface microphotographs with a higher rate of wood.

\subsection{Mechanical Properties of Biocomposites HDPE/Typha Rod}

The following figures show the results of mechanical tensile tests of composites made up of high density polyethylene reinforced by typha stem powder with $25 \%, 35 \%$ and $45 \%$ of weight concentrations. The maximum stress and tensile elastic modulus of the HDPE tend to increase respectively with the reinforcement rates of $35 \%$ and $45 \%$. However, there is a decrease in the maximum deformation at break with the powder concentration.

The slight fall in the maximum tensile stress observed when the wood particle content exceeded 35\% (Figure 7(b)), is due to the formation of particles agglomeration at high concentrations, resulting in poor adhesion between the powder and the polymer matrix. Thus, one might think that there is an optimal concentration value for the manufacture of HDPE/typha stem composite. The weight 
ratios of the powder increasing below this optimum value would cause a good content distribution in the polymer matrix; the direct consequences would be to obtain better tensile properties (Figure 7 (a) and Figure 7(b)). However, an additional increase that is higher than the optimum mass value of powder would result in a decrease in tensile strain (Figure $7(\mathrm{c})$ ), as described by most of the authors [41] [42].

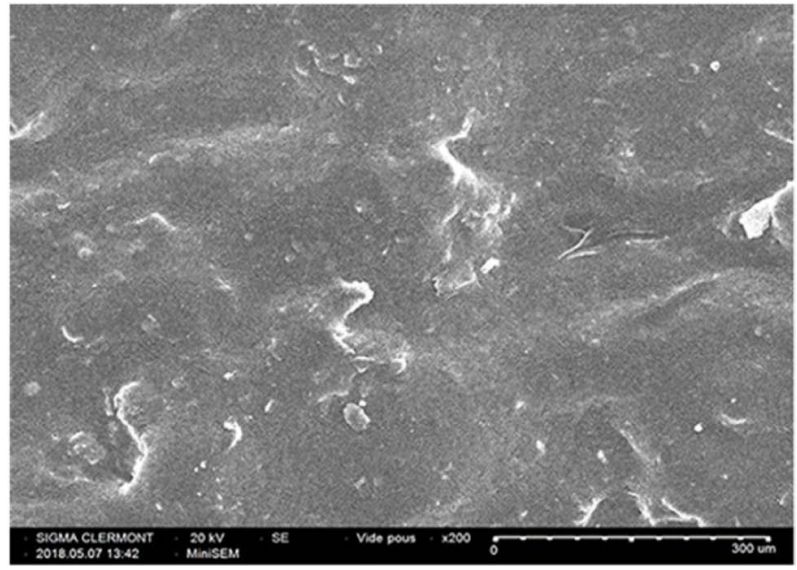

(a)

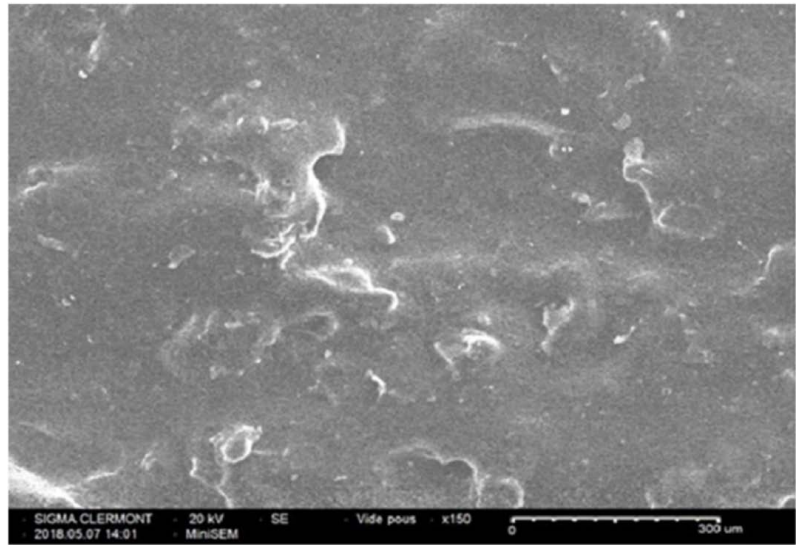

(b)

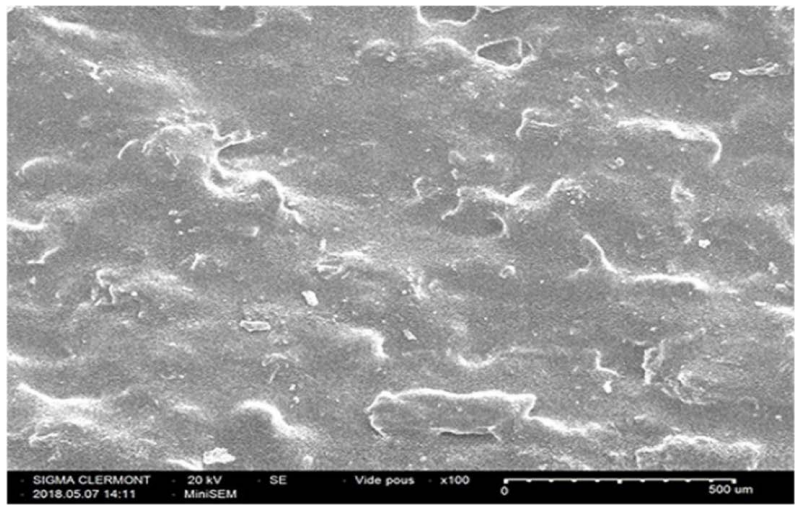

(c)

Figure 6. SEM images of HDPE composites: (a) HDPE/25 RD; (b) HDPE/35 RD; and (c) HDPE/45 RD. 


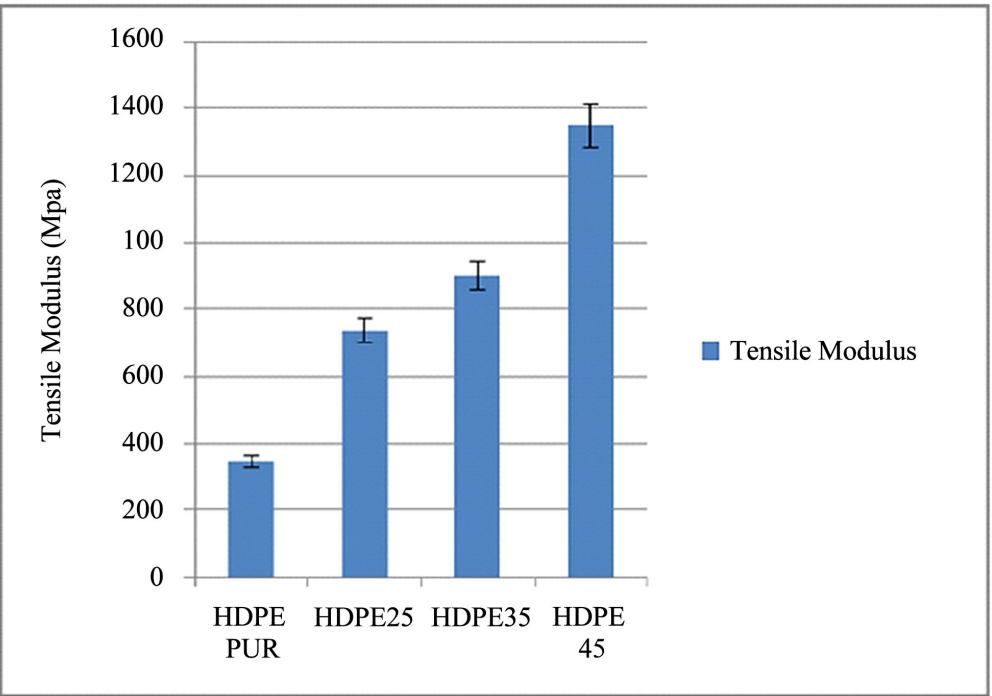

(a)

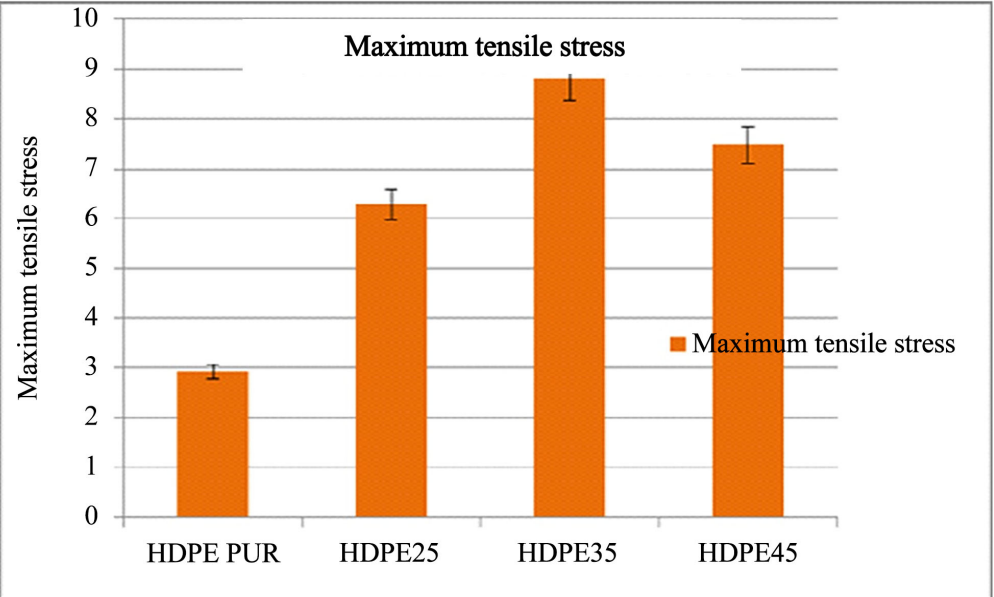

(b)

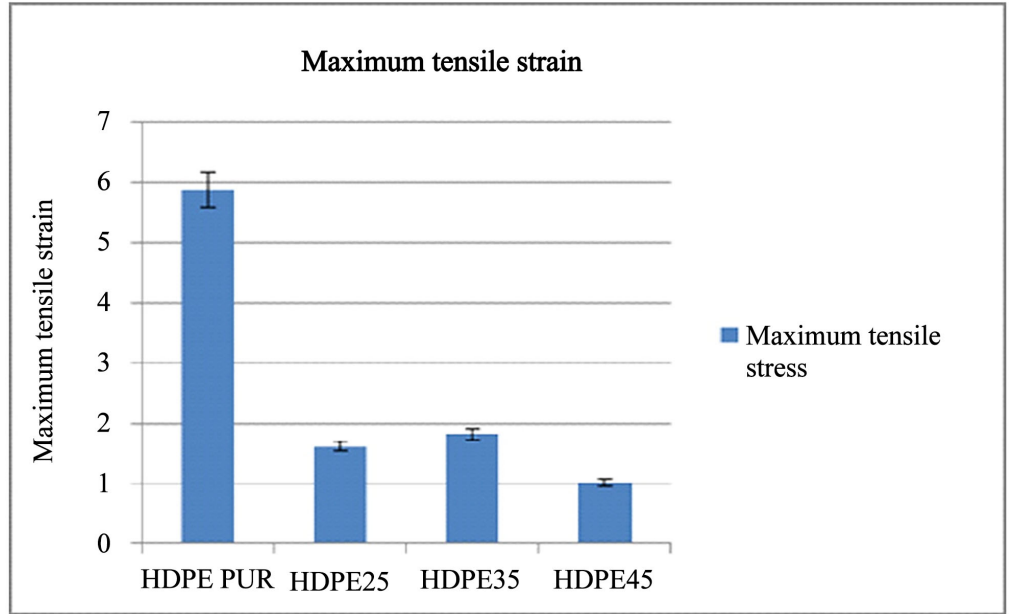

(c)

Figure 7. (a) The Tensile Young modulus of pure HDPE and its composites; (b) The Maximum tensile stress of pure HDPE and its composites; (c) The Maximum tensile strain of pure HDPE and its composites. 


\section{Conclusions}

The properties of mixtures made up of HDPE and typha stem flour have been studied. The dynamic behavior of the moduli in the molten state shows their increase for different powdered flour concentrations. In low frequency ranges, the Newtonian viscosity increased as the percentage of typha stem flour increased. However, the viscosity decreased with the increase of the frequency, which shows shear thinning behavior of the biocomposites.

Concerning the thermal properties of the composites, an increase in the crystallinity and a loss of more than $90 \%$ of mass were noted. The typha stem had served as a nucleating agent, and it caused a modification of the kinetic crystallization of the biocomposites.

Morphological analysis showed the state of the wood powder dispersion in the composite; it was observed that there was a better dispersion for the concentrations with $25 \%$ and $35 \%$ of powder. Tensile modulus and maximum deformation increased considerably with powder.

\section{Acknowledgements}

The authors wish to thank the African Center of Excellence in Mathematics, Computer Science and Technology of Information and Communication (CEA-MITIC) of Gaston Berger University for supporting a part of the research program.

\section{Conflicts of Interest}

The authors declare no conflicts of interest regarding the publication of this paper.

\section{References}

[1] Salit, M.S. (2014) Tropical Natural Fibers Composites: Properties, Manufacture and Applications. Springer Engineering Materials, Singapore.

[2] Stark, N.M. and Rowlands, R.E. (2003) Effects of Wood Fiber Characteristics on Mechanical Properties of Wood/Polypropylene Composites. Wood and Fiber Science, 35, 167-174.

[3] Porteous, J. and Kermani, A. (2013) Structural Timber Design to Eurocode 5. John Wiley \& Sons, Hoboken.

[4] Gisele, C.X. and Valle Maria, I.B. (2007) Effect of Wood Content on the Thermal Behavior and on the Molecular Dynamics of Wood/Plastic Composites. Macromolecular Symposia, 258, 113-118.

[5] Ali, M.A., Khan, M.A., Ali, K.M.I., Khan, F. and Ahmad, S.R. (1999) Preparation of Jute-Plastic Composite by the Preirradiation Method. Journal Polymer-Plastics Technology and Engineering, 38, 739-752. https://doi.org/10.1080/03602559909351610

[6] Ashori, A. (2008) Municipal Solid Waste as a Source of Lignocellulosic Fiber and Plastic for Composite Industries. Polymer-Plastics Technology and Engineering, 47, 741-744. https://doi.org/10.1080/03602550802188565 
[7] Maiti, S.N. and Singh, K. (1986) Influence of Wood Flour on the Mechanical Properties of Polyethylene. Journal of Applied Polymer Science, 32, 4285-4289. https://doi.org/10.1002/app.1986.070320341

[8] Chen, H.C. and Chen, T.Y. (2007) Effects of Wood Particle Size and Mixing Ratios of HDPE on the Properties of the Composites. Holz als Roh-und Werkstoff, 64, 172-177. https://doi.org/10.1007/s00107-005-0072-X

[9] da Silva, A.L.N., Rocha, C.G., Moraes, M.A.R., Valente, C.A.R. and Coutinho, F.M.B. (2002) Mechanical and Rheological Properties of Polyolefin Composites and Mineral Additives. Polymer Testing, 21, 57-60. https://doi.org/10.1016/S0142-9418(01)00047-2

[10] Shenoy, A.V. (1999) Rheology of Highly Filled Polymer Systems. Kluwer, Londres. https://doi.org/10.1007/978-94-015-9213-0

[11] George, J., Sreekala, M.S. and Thomas, S. (2001) A Review on Interface Modification and Characterization of Natural Fiber Reinforced Plastic Composites. Polymer Engineering and Science, 41, 1471-1585. https://doi.org/10.1002/pen.10846

[12] Youngquist, J.A. (1995) The Marriage of Wood and Non-Wood Materials. Forest Products, 45, 25-30.

[13] Pardo, S.G., Bernal, C., Ares, A., Abad, M.J. and Cano, J. (2010) Rheological, Thermal,and Mechanical Characterization of FlyAsh-Thermoplastic Composites with Different Coupling Agents. Polymer Composites, 31, 1722-1730. https://doi.org/10.1002/pc.20962

[14] Hristov, V. and Vasileva, S. (2003) Dynamic Mechanical and Thermal Properties of Modified Polypropilene Wood Fiber Composites. Macromolcular Materials and Engineering, 288, 798-806.

[15] Hristov, V., Takacs, E. and Vlachopoulos, J. (2005) Viscoelastic Behavior of Highly Filled HDPE/Wood Flour Composites. ANTEC, Conference Proceedings, Vol. 73, 1331-1335.

[16] Hristov, V., Takacs, E. and Vlachopoulos, J. (2003) Surface Tearing and Wall Slip Phenomena in Extrusion of Highly Filled HDPE/Wood Flour Glass Hybrid II. Chemical Modification. Applied Polymer Science, 83, 443-450.

[17] Li, T.Q. and Wolcott, M.P. (2003) Rheology of HDPE-Wood Composites. I. Steady State Shear and Extensional Flow. Composites Partie A: Applied Science and Manufacturing, 35, 303-311. https://doi.org/10.1016/j.compositesa.2003.09.009

[18] Li, T.Q. and Wolcott, M.P. (2003) Rheology of Wood Plastics Melt. Part 1. Capillary Rheometry of HDPE Filled with Maple. Polymer Engineering and Science, 85, 549-559.

[19] Mohanty, S., Verma, S.K. and Nayak, S.K. (2003) Rheological Characterization of HDPE/Jute Composite Melts. Journal of Applied Polymer Science, 99, 1476-1484. https://doi.org/10.1002/app.22661

[20] Ponnukrishnan, P., Chithambara Thanu, M. and Richard, S. (2014) Mechanical Characterization of Typha domingensis Natural Fiber Reinforced Polyester Composites. American International Journal of Research in Science, Technology, Engineering \& Mathematics, 6, 241-244.

[21] Ma, X. and Wang, C. (2009) Impacts of the Physiochemical Properties of Chlorinated Solvents on the Sorption of Trichloroethylene to the Roots of Typha latifolia. Environmental Pollution, 157, 1019-1023. https://doi.org/10.1016/j.envpol.2008.10.005

[22] Pandey, V.C., Singh, N., Singh, R.P. and Singh, D.P. (2014) Rhizoremediation Po- 
tential of Spontaneously Grown Typha latifolia on Fly Ash Basins: Study from the Field. Ecological Engineering, 71, 722-727.

https://doi.org/10.1016/j.ecoleng.2014.08.002

[23] Ciria, M.P., Solano, M.L. and Soriano, P. (2005) Role of Macrophyte Typha latifolia in a Constructed Wetland for Wastewater Treatment and Assessment of Its Potential as a Biomass Fuel. Biosystems Engineering, 92, 535-544.

https://doi.org/10.1016/j.biosystemseng.2005.08.007

[24] Luamkanchanaphan, T., Chotikaprakhan, S. and Jarusombati, S. (2012) A Study of Physical, Mechanical and Thermal Properties for Thermal Insulation from Narrow-Leaved Cattail Fibers. APCBEE Procedia, 1, 46-52. https://doi.org/10.1016/j.apcbee.2012.03.009

[25] Jahan, M.S., Islam, M.K., Chowdhury, D., Iqbal Moeiz, S.M. and Arman, U. (2007) Pulping and Papermaking Properties of Pati (Typha). Industrial Crops and Products, 26, 259-264. https://doi.org/10.1016/j.indcrop.2007.03.014

[26] Xiong, C., Gong, W. and Qi, R. (2009) The Preparation and Properties of Wood Flour/High Density Polyethylene Composites by In-Situ Reaction Extrusion. Polymers for Advanced Technologies, 20, 273-279. https://doi.org/10.1002/pat.1262

[27] Clemons, C. (2002) Wood-Plastic Composites in United States: The Interfacing of Two Industries. Forest Products, 52, 10-18.

[28] Ndiaye, D. (2012) Contribution to the Study of the Characterization, Physico-Mechanical Properties and Photo Aging Process of Polymer Wood Composites. Ph.D. Thesis, Cheikh Anta DIOP University, Dakar.

[29] Niang, B., Ndiaye, D. and Lô Kholl, M. (2017) Gamma-Radiation-Induced HDPE/Wood Composite: Studies of Morphological, Mechanical and Thermal Properties of the Composites. Chemical International Journal, 20, 1-12. https://doi.org/10.9734/CSJI/2017/37423

[30] Penava, N.V., Rek, V. and Houra, I.F. (2013) Effect of EPDM as a Compatibilizer on Mechanical Properties and Morphology of PP/LDPE Blends. Journal of Elastomers \& Plastics, 45, 391-403. https://doi.org/10.1177/0095244312457162

[31] Kim, H.S., Yang, H.S., Kim, H.J. and Park, H.J.J. (2004) Thermogravimetric Analysis of Rice Husk Flour Filled Thermoplastic Polymer Composites. Journal of Thermal Analysis and Calorimetry, 76, 395-404. https://doi.org/10.1023/B:JTAN.0000028020.02657.9b

[32] Badji, A.M., Ly, E.B. and Ndiaye, D. (2016) The Effect of Poly-Ethylene-Co-Glycidyl Methacrylate Efficiency and Clay Platelets on Thermal and Rheological Properties of Wood Polyethylene Composites. Advanced in Chemical Engineering and Science, 6, 2-7. https://doi.org/10.4236/aces.2016.64040

[33] Ndiaye, D., Badji, A.M. and Tidjani, A. (2016) Physical Changes Associated with Gamma Doses on Wood/Polypropylene Composites. Journal of Composite Materials, 48, 3063-3071.

[34] Bailon, J.P. and Dorlot, J.M. (2000) Matériaux. Presses Internationales Polytechniques, Montréal, 736.

[35] Michaud, F. (2003) Rheology of Wood/Thermoplastic Composite Panels under Thermomechanical Loading: Postforming Aptitude. Ph.D. Thesis.

[36] Crowson, R.J., Folkes, M.J. and Bright, P.F. (1980) Rheology of Short Glass Fiber-Reinforced Thermoplastics and Its Application to Injection Molding I. Fiber Motion and Viscosity Measurement. Polymer Engineering \& Science, 20, 925-933. https://doi.org/10.1002/pen.760201403 
[37] Qin, H., Zhang, S. and Zhao, C. (2004) Thermalstability and Flammability of Polypropylene/Montmorillonite Composites. Polymer Degradation and Stability, 85, 807-813.

[38] Crowson, R.J. and. Folkes, M.J. (1980) Rheology of Short Glass Fiber-Reinforced Thermoplastics and Its Application to Injection Molding. II. The Effect of Material Parameters. Polymer Engineering \& Science, 20, 934-940.

https://doi.org/10.1002/pen.760201404

[39] Sombatsompop, N. and Dangtungee, D.R. (2002) Effects of the Actuel Diameters and Diameters Ratios of Barrels and Dies on the Elastic Swell and Entrance Pressure Drop of Natural Rubber in Capillary Die Flow. Journal of Applied Polymer Science, 86, 1762-1772. https://doi.org/10.1002/app.11212

[40] Marcovich, N.E., Reboredo, M.M., Kenny, J. and Aranguren, M.I. (2003) Rheology of Particle Suspensions in Viscoelastic Media. Wood Flour-Polypropylene Melt. Rheologica Acta, 43, 293-303. https://doi.org/10.1007/s00397-003-0349-0

[41] Facca, A.G., Kortschot, M.T. and Yan, N. (2007) Predicting the Tensile Strength of Natural Fibre Reinforced Thermoplastics. Composites Science and Technology, 67, 2454-2466. https://doi.org/10.1016/j.compscitech.2006.12.018

[42] Facca, A.G., Kortschot, M.T. and Yan, N. (2007) Predicting the Elastic Modulus of Natural Fiber Reinforced Thermoplastics. Composites Part A: Applied Science and Manufacturing, 37, 1660-1667. https://doi.org/10.1016/j.compositesa.2005.10.006 